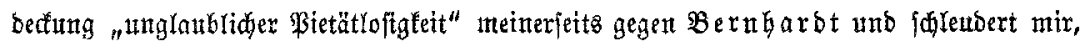

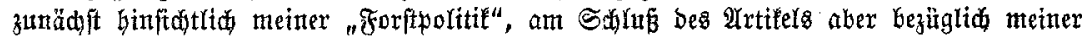

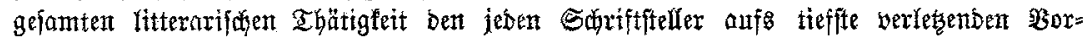

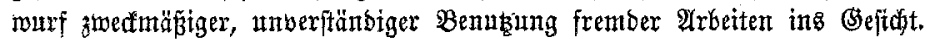

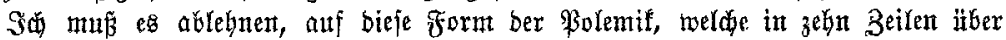

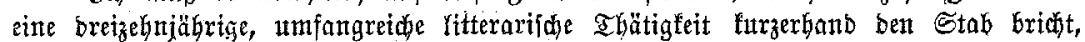
zu antworten anto granbe bas Urteil ïber meine Reifungen einerjeits unb eine berartige

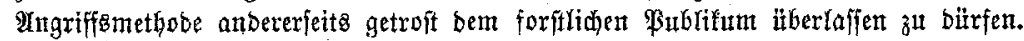

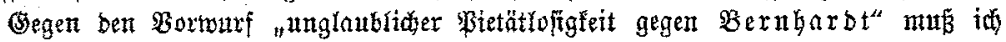
entfofieben Protefi einlegen.

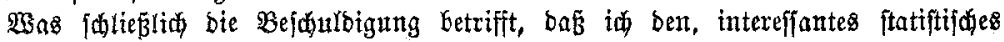

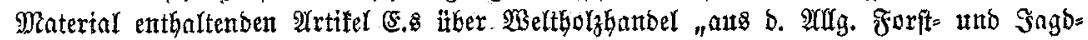

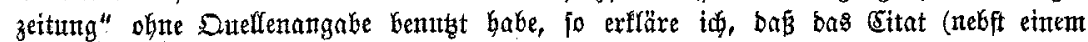

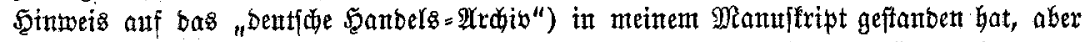
zu meinem Bebauern bon bem Seerauzgefer bez gejanten 2 Berfes, Serrn Dozenten Dr. Franfenftein aus pringipiellen sritnben geftriden wurbe, bas Gleide gilt fir

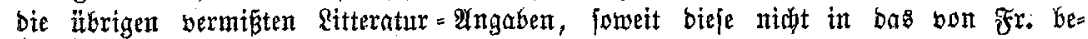
arbeitete \&itteratur $=$ Berzeidunis iibernommen worben fint.

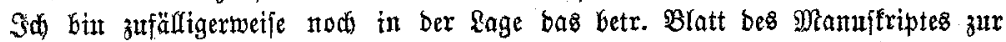

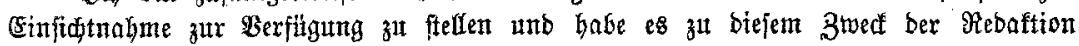
Diejer Beitidirifit ỉberjant.

(Ebergivalbe, ఏen 18. Mărz 1896.

Prot. Dr. Squappad.

\title{
Anmerfung $\mathfrak{u}$ voriteh̨ender Erwiderung.
}

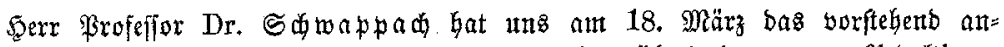

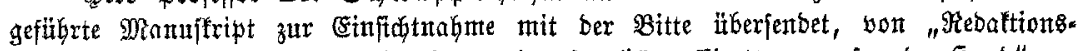

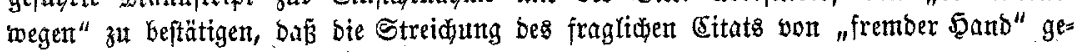
foseben feit.

3ur Sadie geftatten wix uns folgenbes betz̆ufügen:

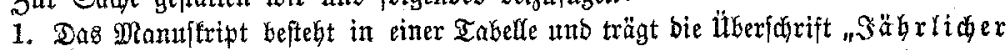

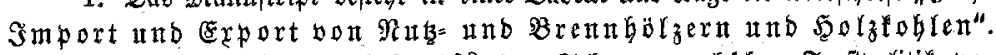

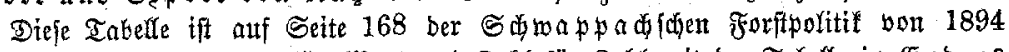

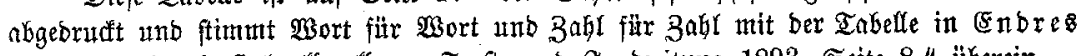

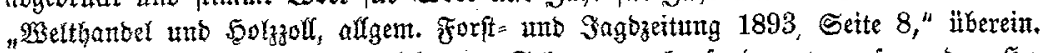

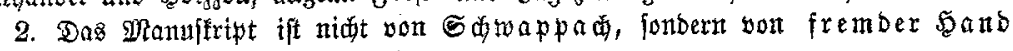
(wohl von etnen Suretber?) gefdrieben.

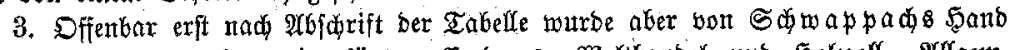

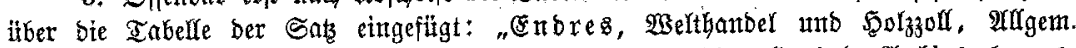

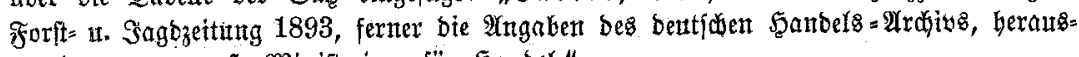
gegeben vom preußi. Mintiferium für Sganbel."

Restersa Gitat wurbe aber mieber burdftriden, dh̆te baf zut erfennen iff, burdh went ber albitrid, erfolgte.

Mitutthen, 18. Aprit 1896.

Die Rebrftion. 